\title{
Mechanistic Paradigms of Natural Plant Metabolites as Remedial Candidates for Systemic Lupus Erythromatosus
}

\author{
Acharya Balkrishna ${ }^{1,2}$, Pallavi Thakur ${ }^{1}$, Shivam Singh ${ }^{1}$, Swami Narsingh Chandra Dev ${ }^{1}$ and \\ Anurag Varshney 1,2,*(D) \\ 1 Drug Discovery and Development Division, Patanjali Research Institute, NH-58, Haridwar, \\ Uttarakhand 249 405, India \\ 2 Department of Allied and Applied Sciences, University of Patanjali, Patanjali Yog Peeth, Roorkee-Haridwar \\ Road, Haridwar, Uttarakhand 249 405, India \\ * Correspondence: anurag@prft.co.in; Tel.: +91-1334-240008
}

Received: 29 February 2020; Accepted: 14 April 2020; Published: 22 April 2020

check for updates

\begin{abstract}
Systemic lupus erythematosus (SLE) is a complex autoimmune disorder involving a dysregulated immune response which ultimately leads to multiple organ failure. Several immunological and cellular checkpoints are available as drug targets. However, the available chemosynthetic drugs such as non-steroidal anti-inflammatory drugs and corticosteroids provide limited therapy with extreme toxicities. Moreover, the disease heterogeneity in SLE is very difficult to manage by a single drug component. Hence, it is imperative to utilize the holistic capabilities of natural plant products as immunomodulators and intracellular signaling regulators, thereby providing an auxiliary option of treatment. Additionally, the herbal drugs also serve as symptomatic relief providers, thereby serving as a prophylactic remedy in case of cerebrovascular, hepatic, nephropathological, hematological, cardiopulmonary, mucocutaneous and musculoskeletal manifestations of SLE. The present review attempts to showcase the current state of knowledge regarding the utility of plant-derived phyto-metabolites with their probable mechanistic roles in treating SLE, by means of targeting the signaling cascade, proinflammatory cytokine production and B-T cell co-stimulation. It is hoped that further preclinical and clinical studies will be embarked upon in order to understand the underlying therapeutic and mechanistic aspects of these medicinal herbs.
\end{abstract}

Keywords: autoimmunity; immune regulation; natural plant products; systemic lupus erythematosus; herbal medicines

\section{Introduction}

Systemic lupus erythromatosus (SLE) is a chronic, incapacitating autoimmune disorder with an unusual trend of latency and relapses, mainly afflicting women of Asian, African or American ethnicities [1]. The unpredictable course of relapsing and remissions makes it difficult to diagnose [2]. Moreover, there is no absolute treatment regime for this ailment. However, certain immunosuppressive steroids offer a limited therapeutic way of providing symptomatic relief. As a consequence, these steroids often render the SLE patients susceptible to opportunistic infections $[3,4]$.

The main etiological factors responsible for causing SLE primarily include genetic factors (presence of inflammation triggering genes, toll-like receptor expressing genes and STAT signaling pathway genes) $[1,5,6]$. The genetic structures of SLE-responsive individuals have also exhibited the absence/masking of DNA repair genes such as TREX1, KLK1 and KLK3 [7-9].

Certain epigenetic changes such as post-translation modification of histones and DNA methylation often induce susceptibility to SLE. External factors such as ultraviolet rays, demethylating drugs 
(Azacitidine, Decitabine) and viral infection (Epstein-Barr virus) often trigger the possibility of occurrence of SLE (Figure 1). Moreover, the higher concentration of hormones like estrogen and prolactin also leads to the upregulation of autoimmune phenotypes and hence, SLE is associated with the female gender more often. Both hormones promote the chances of survival of plasma cells responsible for producing high affinity autoreactive B cells $[10,11]$.

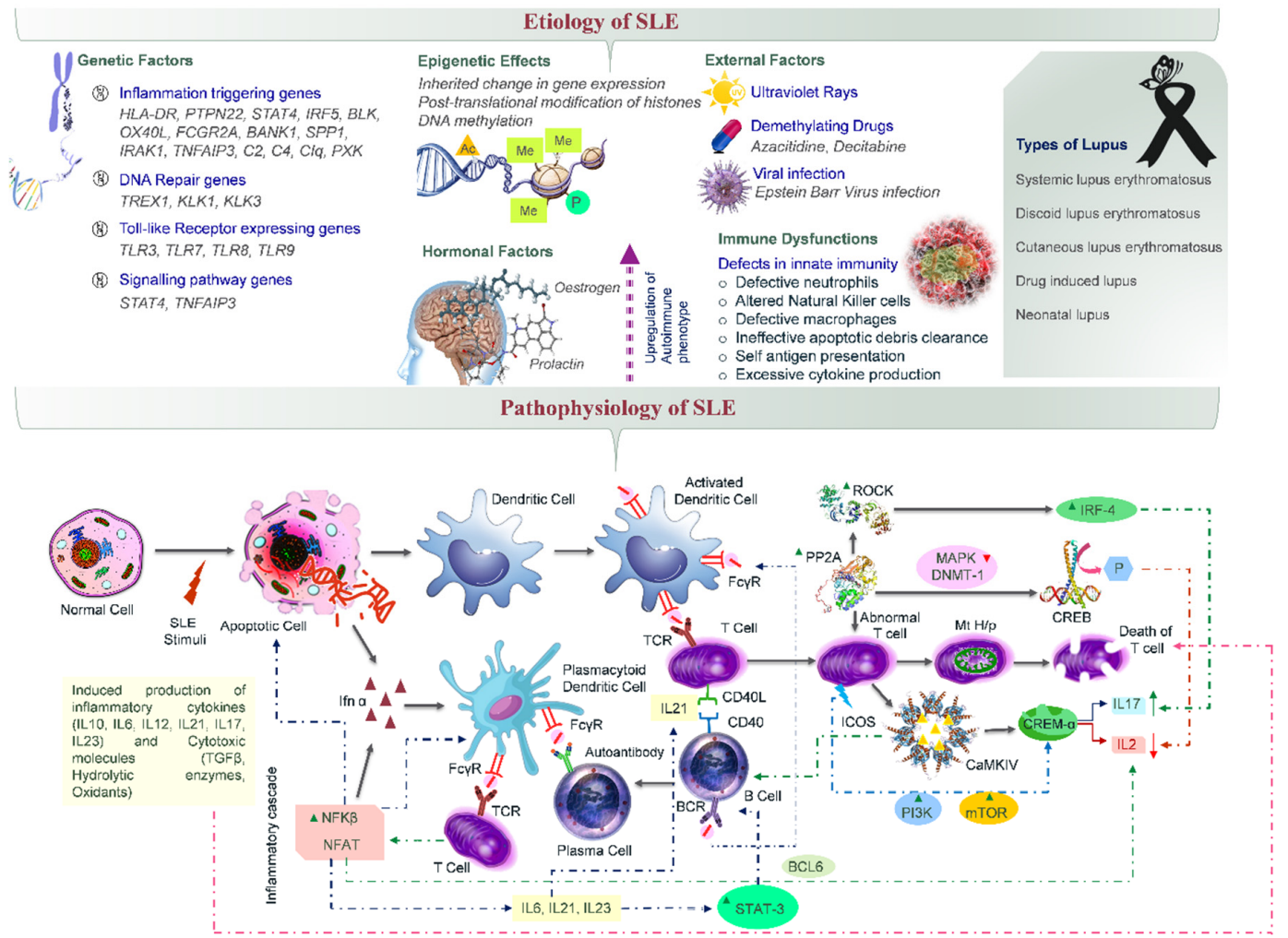

Figure 1. Etiology and pathophysiology of systemic lupus erythromatosus (SLE). Etiology of SLE includes genetic, epigenetic, hormonal, immunological and other external factors. These etiological factors act as a stimulus for inducing apoptosis of a normal cell, thereby breaking the dsDNA which in turn induces the production of interferons (Ifn- $\alpha$ ) [1,10]. These interferons induce the activation of plasmacytoid dendritic cells. Further, the broken DNA acts as an antigen which is presented on dendritic cells (physiologically altered with Fc $\gamma$ R). Meanwhile, T cells and B cells also interact via CD40 and CD40L interaction with the DNA antigen, thereby inducing the production of autoantibodies which further induce the interaction of plasmacytoid dendritic cells and T cells [12-14]. This interaction upregulates the production of NFAT and NFKB, both of which inhibit the production of IL-2 (an immunosuppressive cytokine) and induce the production of BCL6, IL6, IL21 and IL23. These cytokines further upregulate the expression of STAT3 which aids in the co-stimulation of B cells and T cells, thereby leading to the production of autoantibodies [13-15]. These autoantibodies induce SLE-related manifestations and a simultaneous signaling cascade also commences. Protein phosphatase 2 (PP2A) initiates a 3-tier phenomenon [16], i.e.: mitochondrial hyperpolarization and the death of T cells [17-19]; activation of Rho-associated protein kinase (ROCK) which further mediates the binding of IL17 transcription enhancer interferon regulatory factor 4 (IRF4) [20]; dephosphorylation of cAMP-responsive element-binding protein 1 (CREB), resulting in suppression of IL2 transcription (mediated by downregulation of expression of MAPK—-mitogen-activated protein kinase and DNMT1—DNA methyl transferase 1) [21]. Further upregulation of IL17 and downregulation of IL2 production is mediated by calcium/calmodulin-dependent protein kinase IV (CaMKIV), which in turn increases the binding of cAMP response element modulator $(\mathrm{CREM} \alpha)$ [12-18]. Certain co-stimulatory signaling molecules such as ICOS (Inducible T cell co-stimulator), PI3K (phosphoinositide 3-kinase) and mTOR (mechanistic target of Rapamycin) also aid in similar interleukin regulation [12]. 
All these etiological factors lead to certain immune dysfunctionalities (defective neutrophils, macrophages and natural killer cells), thereby causing the immune system to attack its own cells and destroy multiple organ systems including the cardiovascular, mucocutaneous, cerebrovascular and pulmonary systems, etc., ultimately leading to SLE [8]. Characteristic symptoms of the disease include maculopapular (e.g., malar or discoid, butterfly shaped facial and cutaneous rashes), mucocutaneous (oral ulcers), musculoskeletal (arthritis and osteomyelitis), cerebrovascular (cranial neuropathies and cognitive impairments), hepatic (hepatomegaly, cholecystitis), renal (nephritis, proteinuria) and cardiopulmonary manifestations (pericarditis, pneumonitis). Autoantibodies against the nuclear body, ribonucleoproteins and DNA are formed in SLE. Moreover, the immunological and hematopoietic cells of the body are also attacked by autoantibodies, thereby causing severe damage to the blood cells as reflected by hemolytic anemia, leukopenia and thrombocytopenia [17]. Further secondary manifestations are also observed wherein the vital organs such as the liver, heart, lungs and kidneys undergo acute failure, thereby increasing morbidity and mortality (Figure 2).

Most of the clinical manifestations of the disease are associated with certain pathophysiological cascades, particularly involving the hyperactivation of the immune response and abnormality in the immune regulation system. Proinflammatory cytokines, namely IL6, IL10, IL12, IL17, IL21 and IL23, are produced in excess as mediated by rho associated protein kinase (ROCK); transcription factors, namely STAT3 and CREM $\alpha$; nuclear factor NFKB and NFAT, thereby leading to the co-stimulation of B and $\mathrm{T}$ cells, ultimately causing the excessive production of autoantibodies. Furthermore, transcription and nuclear factors, such as CREB, NFKB and NFAT also lead to the production of BCL6 which downregulates the production of immunoregulatory cytokines, i.e., IL2 [12-18]. Excessively produced autoantibodies lead to DNA and ribonucleoprotein damage in healthy cells, leading to mass apoptosis. Hence, both autoantibodies and inflammatory cytokines are responsible for aggravating the pathology of SLE $[13,14]$.

This disease follows an erratic course of latency and recurrence, thereby making its prognosis and diagnosis difficult [2]. Current therapeutic strategies of this disease are also limited to the use of steroids and cytotoxic drugs. These remedial regimes also possess the limitations of exorbitant costs and the induction of multiple organ toxicity. Hence, SLE can be designated as a life-threatening disease wherein diagnosis and therapeutic challenges still exist. There is an urgent need for the investigation on better therapeutic approaches for targeting the etio-pathogenic mechanisms of SLE [3]. The toxicological profiles of currently available chemotherapeutic drugs advocate the exploratory search for natural remedial sources for the management of SLE. As a matter of fact, combinatorial therapies of chemosynthetic drugs and holistic nutraceuticals can also be examined for assessing the possibilities of immuno-augmentation [22]. The following sections present the mechanistic roles of phytoconstituents with their natural sources as promising remedial targets for various pathophysiological checkpoints of SLE (Table 1). 


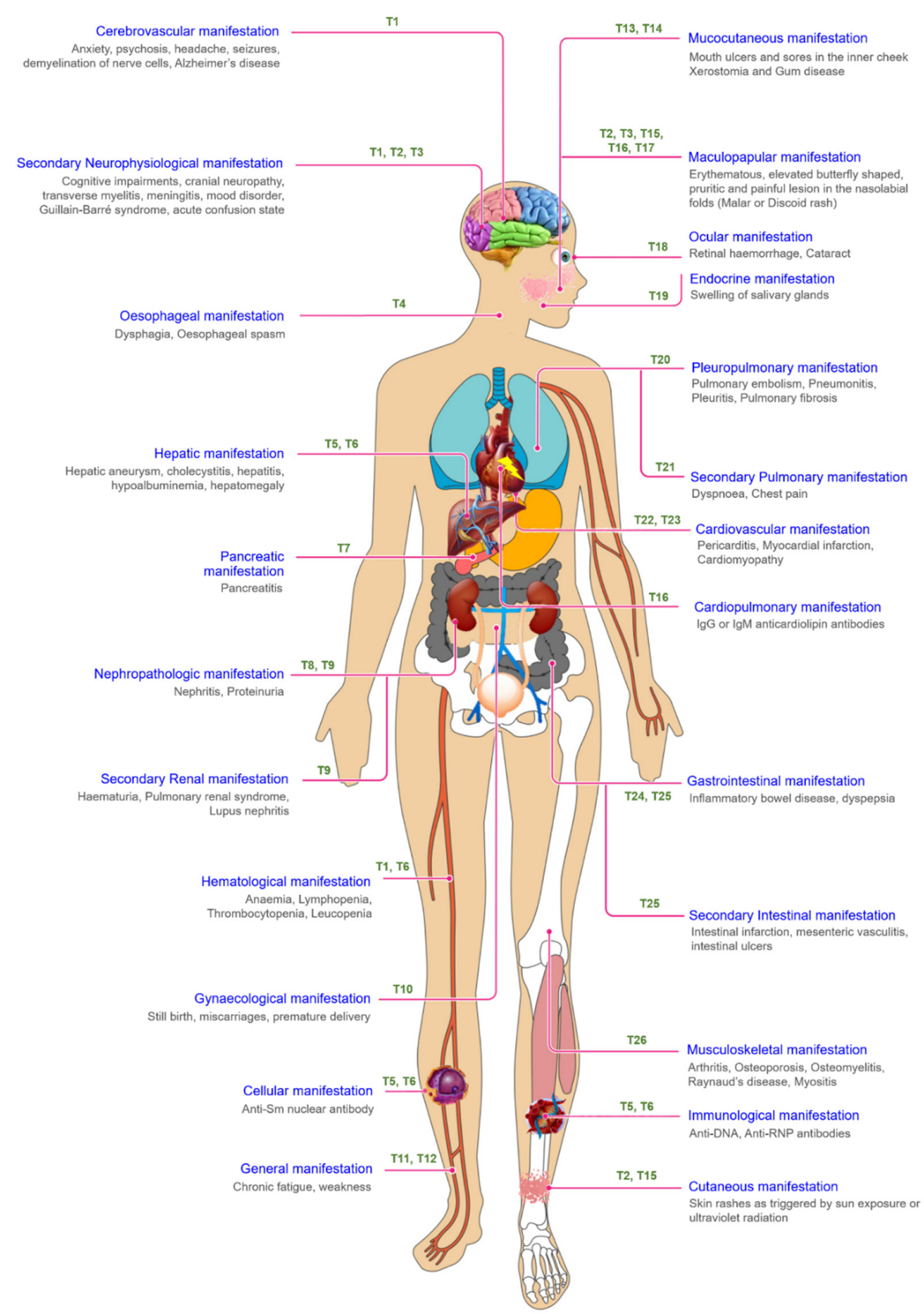

Figure 2. Clinical manifestations of systemic lupus erythromatosus along with therapeutic interventions. Systemic lupus erythromatosus is a chronic autoimmune disease targeting various systems of the human body including the cardiovascular, cerebrovascular, gastrointestinal, gynecological, hematological, hepatic, immunological, mucocutaneous, musculoskeletal, ocular, esophageal, pancreatic, pulmonary and renal systems. The treatment of SLE is centered upon formulating a regimen of topical and systemic therapies designed to reduce both disease severity and activity, wherein various treatment modalities are T1: dapsone and fingolimod; T2: lenalidomide; T3: thalidomide; T4: calcium channel blockers; T5: glucocorticoid prednisone; T6: azathioprine; T7: rifampin; T8: chaperonin 10; T9: mycophenolate mofetil; T10: misoprostol; T11: iron supplements; T12: vitamin B complex; T13: benzocaine; T14: salbutamol; T15: clofazimine; T16: IVIG (intravenous immunoglobulin); T17: cefuroxime; T18: quinacrine; T19: NSAIDs (non-steroidal anti-inflammatory drugs); T20: methylprednisolone; T21: ipatropium bromide; T22: ibuprofen; T23: aspirin; T24: corticosteroids; T25: aminosalicylate; and T26: methotrexate. 
Table 1. Major phyto-metabolites along with their targeted utility as therapeutic potentials for systemic lupus erythromatosus.

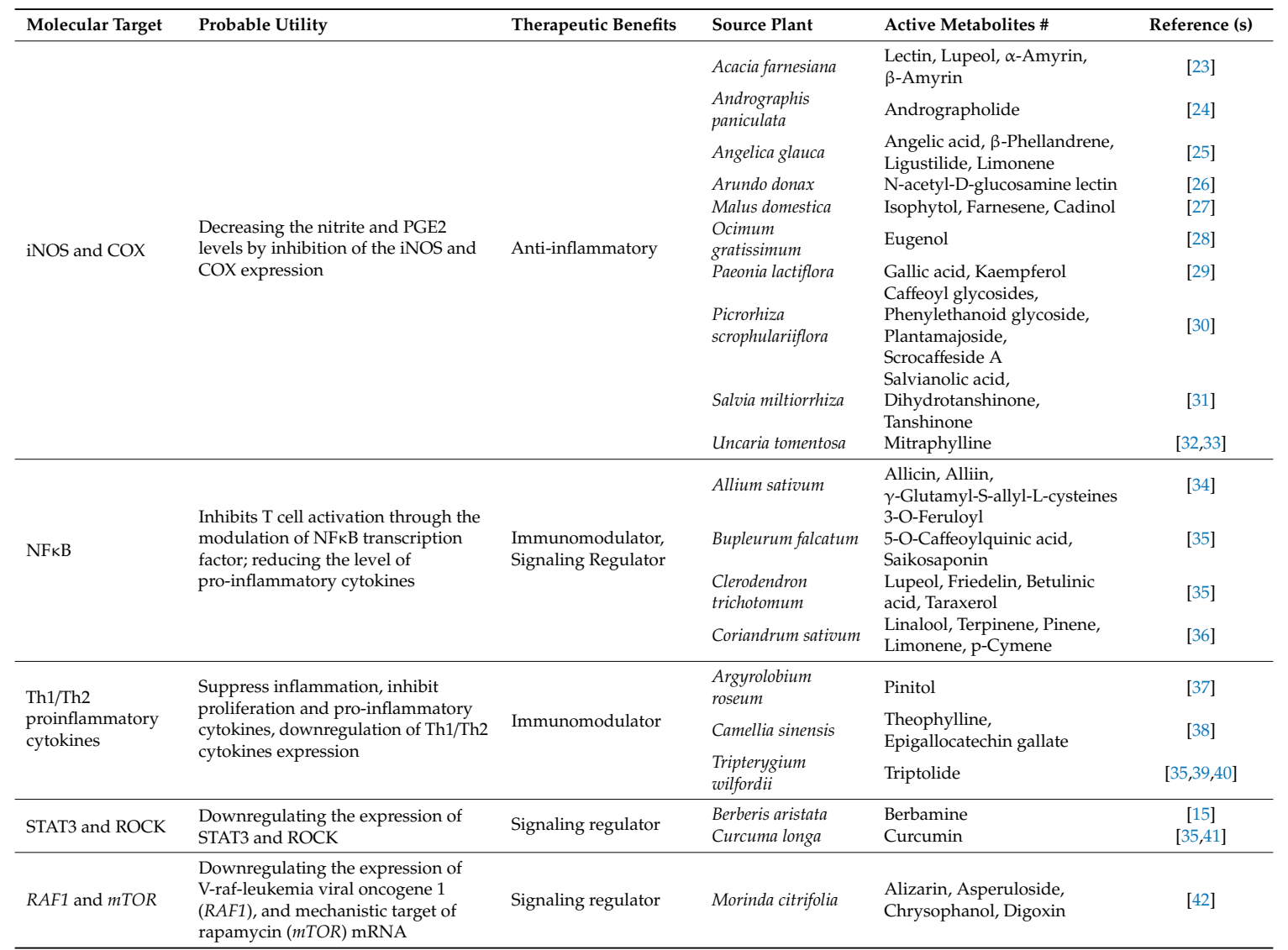

\# Active phytoconstituents that may serve as phyto-ligands for assessing the structure-activity relationships, thereby generating a pharmacophore.

\section{Chemotherapeutic Modalities for Treating SLE}

The primary remedial regimes for SLE include corticosteroidal drugs, non-steroidal anti-inflammatory drugs (NSAIDs) and antimalarial drugs. These remedies are not absolute but are the only available option for curbing this disease and its related symptoms. Corticosteroids are frequently used to suppress the acute, inflammatory condition of SLE. They are prescribed in either high or low doses for treating severe to long-term manifestations. Unfortunately, a significant proportion of patients still depend on corticosteroids for months to a lifetime. Such dependency on steroids has become a grave clinical problem, wherein any attempt to reduce or discontinue the dose of corticosteroids further aggravates the complications [43]. Moreover, there are several adverse effects of corticosteroids, such as acne, edema, hirsutism, myopathy, hypertension, cataracts and diabetes [44]. In certain cases, prolonged dependency on corticosteroids causes avascular necrosis, osteonecrosis [44,45] and microvascular tamponade from hypertrophy of intraosseous lipocytes [44,46,47].

Besides, nonsteroidal anti-inflammatory drugs (NSAIDs) are universally prescribed to relieve arthralgia, inflammation, serositis and fever in SLE patients [48]. NSAIDs are blockers of cyclooxygenases, the COX-1 and COX-2 enzymes. Such selective inhibition of COX-1 and COX-2 facilitates the production of prostaglandins that reduce inflammation and pain [49-51]. However, these NSAIDs often impart gastrointestinal side effects such as adverse bleeding and antiplatelet effects. Hence, the use of NSAIDs for SLE requires strict caution when prescribed to patients with renal disease or photosensitivity [51]. 
Furthermore, most of the patients with SLE are advised to administer antimalarial drugs (hydroxychloroquine and chloroquine) as auxiliary treatment regimens [8,52]. The mode of action of antimalarial drugs is to inhibit the transcription of intracellular toll-like receptors, thereby ameliorating the autoimmune response [52-54]. Additionally, the antimalarials aid in managing the disease conditions of SLE, such as skin lesions, neoplasm and thromboembolism. However, rampant use of antimalarials often leads to renal and hepatic complications [54].

It is noteworthy that the monoclonal antibody biologic, rituximab, has been investigated for its efficacy against SLE as it induces B cell depletion, thereby controlling the overproduction of autoantibodies [55]. Moreover, the B cell hyperactivity in SLE is associated with the over-expression of a B cell regulator, namely B-cell activity factor $(B A F F)$, which can be downregulated by employing anti-BAFF antibodies [56].

\section{Plant-Derived Natural Compounds for Treating SLE}

A number of plant-derived phytoconstituents are known to exert immunosuppressive effects and hence can be used for the management of autoimmune disorders such as SLE. Phytocompounds belonging to diverse categories as alkaloids (berbamine), lectin (tomato lectin), flavonoids (quercetin), phenolic glycosides (curcumin), terpenoids (azadirachtin) and saponins (ginsenoside) have been found to reduce inflammatory cytokines and intracellular signaling, thereby exerting anti-inflammatory and immunoregulatory effects [15,35]. Moreover, certain natural plant products (e.g., pyrogallol, cynocobalamin, folacin, and bufotenine) have also been found to ameliorate the symptoms associated with SLE (Figure 3). There has been growing interest to explore the anti-inflammatory or immunosuppressive activities of naturally derived phytoconstituents, as they have negligible toxicities and superlative efficiency [57]. The ensuing sections delineate the different categories of immunoregulatory and symptomatic relief providing phytoconstituents.

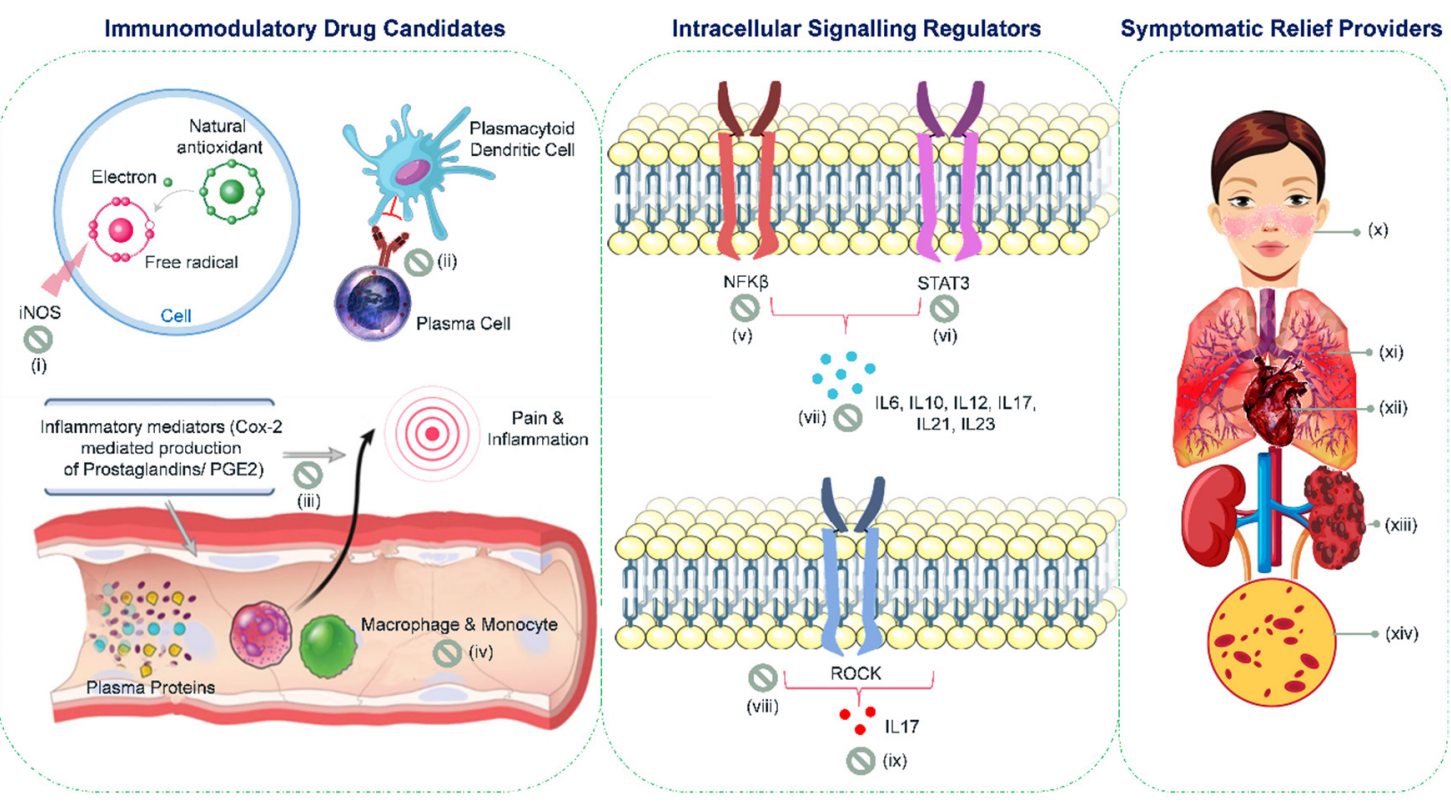

Figure 3. Pharmaco-mechanistic profile of phyto-metabolites in treating systemic lupus erythromatosus. Plant-derived phytoconstituents serve as (i) nitric oxide synthase (iNOS) inhibitors and promote the scavenging of free radicals, thereby preventing SLE associated DNA damage (alizarin, asperuloside, $\alpha$-amyrin, $\beta$-amyrin, andrographolide, angelic acid, cadinol, isophytol, $\beta$-phellandrene, galic acid, 
kaempferol, limonene, lupeol, lectin, scrocaffeside A, salvianolic acid, mitraphylline); (ii) inhibitors of autoantibody production \{linalool acetate, $\alpha$-terpinyl acetate\}; (iii) inhibitors of COX-2-mediated PGE2 production, thereby ameliorating inflammation and pain \{andrographolide, isophytol, farnesene, cadinoleugenol, troptolide\}; (iv) inhibitors of lymphocyte proliferation \{limonene, carvacrol, terpinene, calycopterin\}; (v) down-regulators of NFKB -mediated signaling \{allicin, alliin- $\gamma$-glutamyl-S-allyl-L-cysteine, andrographolide, saikosaponin, epigallocatechin gallate, lupeol, taraxerol, friedelin, betulinic acid, linalool, pinene, terpinene, limonene, curcumin\}; (vi) down-regulators of STAT3-mediated signalling \{berbamine, curcumin\}; (vii) inhibitors of production of proinflammatory cytokines \{allicin, alliin- $\gamma$-glutamyl-S-allyl-L-cysteine, pinitol, theophylline, epigallocatechin gallate, curcumin, periplocoside E, triptolide\}; (viii) down-regulators of the expression of Rho-associated protein kinase (ROCK) \{curcumin\}; (ix) inhibitors specifically of the production of IL-17 \{curcumin, quinone, phenylpropanoids, steroids, periplocoside E\}; (x) a topical remedy for butterfly shaped cutaneous lesions \{ecdysterone, oleanolic acid, pyrocatechol, allicin, aloin, aloe emodin, $\beta$ carotene, $\beta$ sitosterol, azadirachtin, cynocobalamin, Plastoquinone, xanthone, coumarin, lycopenecurcubitacin, rosmarinic acid\}; (xi) a pulmonary protectant remedy \{bixin, ledol, ascaridole\}; (xii) a cardioprotectant remedy \{tyramine, pseudoephedrine, bufotenine, papaverine\}; (xiii) a nephroprotectant remedy \{cimicifugic acid, protocatechuic acidephedrineferulic acid, gallic acidchavicine, piperine\}; (xiv) a hematopoietic remedy \{cynocobalamin, folacin, flavolignans, $\beta$ carotene, ginsenoside, etc.\}.

\section{Natural Sources of Immunoregulatory Drug Candidates}

Phytocompounds have emerged as safer immunomodulatory therapeutics and have been used since time immemorial. These phytoconstituents serve as immunoregulatory drug candidates by means of either downregulating the functions of immune cells or by controlling the production of inflammatory cytokines, thereby maintaining immune homeostasis [35]. The main mechanism behind the action of a natural immunosuppressant is dependent on its antagonistic action on oxidative stressors, that ultimately leads to the formation of free radicals targeting the cytokines and autoantibodies. Such immunomodulation has been shown to be exerted by a number of plants, namely Acacia farnesiana, Allium sativum, Andrographis paniculata, Angelica glauca, Arundo donax, Camellia sinensis, Commelina benghalensis, Coriandrum sativum, Costus speciosus, Curcuma longa, Cymbopogon citratus, Dracocephalum rupestre, Malus domestica, Morinda citrifolia, Ocimum gratissimum, Paeonia lactiflora, Picrorhiza scrophulariiflora, Salvia miltiorrhiza and Uncaria tomentosa, etc. These plants contain one or more phytoconstituents that exhibit an exclusive antioxidant or anti-inflammatory activity. These phytoconstituents may also act as modulators of cytokine production and B-T cell co-stimulation, thereby eliminating the chances of the formation of autoantibodies and hyperactivation of the immune response in the case of SLE [58-61]. Further details of the category of phytoconstituents present in the immunosuppressive plants are elucidated in Table 1.

\section{Phytoconstituents as Intracellular Signaling Regulators}

Certain natural plant products are known to exhibit a strong anti-inflammatory activity by means of regulating the expression of various signaling protein kinases and cell cycle proteins which are involved in the transcription of inflammatory cytokines and autoantibodies. One such example is Curcuma longa (active phytoconstituent: curcumin) which is known to inactivate the transcription of TLR2 and NFKB, both of which are involved in preparing the plasmacytoid dendritic cell for presenting the autoantigens, thereby leading to the production of autoantibodies. Additionally, curcumin is also known to inhibit the expression of STAT3 and hence, downstream activation of proinflammatory cytokines, namely IL17 and BCL6, can be prevented [35,41]. In other studies, it has been found that Tripterygium wilfordii contains a diterpenoid epoxide, namely triptolide which is known to inhibit the transcription of IL-17 and STAT3 [35,39]. Similarly, an alkaloid, namely berbamine, found in Berberis aristata, is known to downregulate the expression of STAT3, and also inhibits the production of interferons that induce apoptotic cascade in SLE [15]. Several other plant species, such as Andrographis paniculata, Argyrolobium roseum, Artemisia vestita, Bupleurum falcatum, Campylotropis hirtella, Clerodendron 
trichotomum, Dracocephalum kotschyi, Periploca sepium and Salvia mirzayanii, have also been found to exhibit similar roles as intracellular signaling regulators and hence may possess probable utility as natural remedies for SLE [35,58,62-64].

\section{Holistic Herbs as Symptomatic Relief Providers}

Conventional medicines for treating SLE include the use of corticosteroids, antimalarial drugs and non-steroidal anti-inflammatory drugs (NSAIDS). However, these treatment regimens offer contingent results that may vary with changing patient profiles. Moreover, all these chemotherapeutic moieties are unsafe for continued use as they may induce organ toxicities [44,45,51]. Under such circumstances, alternative medicine treatments including the use of holistic herbs and natural plant products have gained a thriving interest as a viable remedial option for treating SLE. These holistic herbs have manifold targets and ultimately provide symptomatic relief in the case of SLE, which unfolds in several clinical manifestations and opportunistic ailments as well [35,57,65,66].

The primary clinical manifestations of SLE are cardiovascular, cerebrovascular, hematopoietic, hepatic, mucocutaneous, musculoskeletal, pulmonary and renal afflictions. Phytoconstituents, namely bufotenine (Mucuna pruriens), papaverine (Papaver somniferum), pseudoephedrine (Ephedra sinica), pyrocatechol (Allium cepa, Achillea millefolium), pyrogallol (Anogeissus latifolia), theophylline (Camellia sinensis), tyramine (Crataegus laevigata) and yohimbine (Catharanthus roseus), are known to exhibit symptomatic relief in cases of cardiovascular manifestations. Natural compounds such as tocopherol, arecoline, baicalin, ginkgolide, glabridin, naringenin, quercetin, rosmarinic acid, tangeretin and puerarin particularly, serve as cerebroprotective and neurostimulating remedies. Cynocobalamin and folacin (Aloe vera, Anacardium occidentale, Angelica sinensis, Arachis hypogaea, Avena sativa, Beta vulgaris, Brassica rapa, Medicago sativa, Panax quinquefolius, etc.) serve as hematopoietic and hepatoprotective remedies. Similarly, Ephedra antisyphilitica, Alchemilla arvensis, Bixa orellana, Cimicifuga racemosa, Helianthus annuus, Ledum palustre, Piper longum, etc., serve as remedies for managing renal and pulmonary afflictions. Most specifically, the maculopapular manifestation in the form of butterfly shaped cutaneous rashes can be treated with the aid of herbal drugs such as Achyranthes aspera, Allium cepa, Allium sativum, Aloe vera, Azadirachta indica, Bauhinia variegata, Beta vulgaris, Calendula officinalis, Camellia sinensis, Curcuma longa, Lawsonia inermis, Lycopersicon esculentum, Momordica charantia, Rosmarinus officinalis and Thymus vulgaris $[22,35,58,62,63,67-71]$. The precise understanding of the underlying mechanisms and the predominant phytoconstituents responsible for the remedial activity of these plants would need detailed preclinical and clinical research.

\section{Propitious Drug Candidates}

All the above mentioned plant-derived phyto-molecules exert their anti-SLE effect by one means or the other, such as (i) nitric oxide synthase (iNOS) and COX-2 inhibitors; (ii) autoantibody production inhibitors; (iii) lymphocyte proliferation inhibitors; (iv) NFKB and NFAT-mediated signaling inhibitors; (v) STAT3, CREM $\alpha$ and Rho-associated protein kinase (ROCK) inhibitors; (vi) pro-inflammatory cytokine production regulators; and (vii) symptomatic relief providers. Some of the natural plant products also provide manifold therapeutic benefits as they act upon more than one of the molecular targets of SLE. One such example is Allium sativum which is known to maintain immune system homeostasis by inhibiting Th1 proinflammatory cytokines. Moreover, it also exerts an inhibitory effect on NFKB activation. It has also been proposed as a topical remedy for SLE manifestations, including butterfly shaped cutaneous lesions and oral ulcers [34].

Furthermore, Andrographis paniculata, Camellia sinensis, Coriandrum sativum and Curcuma longa serve as immunomodulatory as well as anti-inflammatory herbs, wherein they probably act via reducing the levels of iNOS, COX-2, PGE2, TNF-alpha, IL-6 and IL-12. Hence, these herbs may aid in suppressing inflammation by inhibiting the proliferation of pro-inflammation cytokines, as well as impeding the activation of NFKB signaling $[24,35,36,38,41]$. 
It is noteworthy that certain phyto-molecules such as alizarin, asperuloside, chrysophanol, digoxin and berbamine isolated from Berberis aristata and Morinda citrifolia serve as specific signaling regulators for downregulating the expression of STAT3, RAF1 and mTOR. Hence, both these herbals may serve as promising sources of lead drug molecules targeting SLE [15,42].

These suggested herbal drug candidates are devoid of any potential toxicity or adverse drug reactions, as evident from their previously published toxicological profiles [57]. Henceforth, looking upon the proposed medicinal utility and negligible toxicities, it is postulated that these herbal metabolites should be tested for clinical development and further human use.

\section{Conclusions}

Systemic lupus erythromatosus is a prevalent autoimmune disorder with life threatening consequences. It causes widespread cutaneous as well as systemic inflammation, thereby leading to multiple organ damage. There is still a dearth of absolute treatment regimens for the appropriate management of this disease, wherein the available synthetic chemotherapeutic drugs possess multiple toxicities. As a consequence, one must utilize the alternative therapeutic modalities in the form of natural plant products as these phytoconstituents have negligible toxicities, if any, and are endowed with holistic therapeutic activities. These phytoconstituents may serve as immunoregulatory moieties, intracellular signaling regulators and symptomatic relief providers. Certain herbals like Allium sativum, Angelica glauca, Camellia sinensis and Curcuma longa may serve to cater manifold benefits as they can aid in both preventing the occurrence of SLE by acting as immunomodulators and managing the consequences of SLE by providing symptomatic relief. These suggested phyto-metabolites act via regulating a specific molecular target and hence can serve as probable drug candidates for developing a suitable pharmacophore. Undoubtedly, more research must be performed to evaluate the mechanistic roles and clinical benefits of these natural plant products before engaging them as the alternative treatment armamentarium of SLE.

Author Contributions: A.B. conceived the presented idea and developed the theory. P.T., S.N.C.D. and S.S. analyzed the available data and co-wrote the paper. A.V. investigated and supervised the findings of this work. A.B. and A.V. provided critical revision of the article and approved its final version for publication. All authors have read and agreed to the published version of the manuscript.

Funding: This research is funded by Patanjali Research Foundation Trust, Haridwar, India.

Acknowledgments: The authors are humbly grateful to Param Pujya Swami Ramdev Ji for the institutional and research supports. The authors gratefully acknowledge the efforts of all the colleagues of the Patanjali Research Institute, for their help in data collection. We are also thankful to Gagan Kumar and Lalit Mohan for their swift administrative supports and encouragements.

Conflicts of Interest: The authors declare no conflict of interest.

\section{References}

1. Sarzi-Puttini, P.; Atzeni, F.; Iaccarino, L.; Doria, A. Environment and systemic lupus erythematosus: An overview. Autoimmunity 2005, 38, 465-472. [CrossRef] [PubMed]

2. Bootsma, H.; Spronk, P.; de Boer, G.; Limburg, P.; Kallenberg, C.; Derksen, R.H.; Wolters-Dicke, J.; Gmelig-Meyling, F.; Kater, L.; Hermans, J. Prevention of relapses in Systemic Lupus Erythematosus. Lancet 1995, 345, 1595-1599. [CrossRef]

3. Adu, D.; Cross, J.; Jayne, D.R. Treatment of Systemic Lupus Erythematosus with Mycophenolate Mofetil. Lupus 2001, 10, 203-208. [CrossRef] [PubMed]

4. Eisenberg, R. Why can't we find a new treatment for SLE? Autoimmunity 2009, 32, 223-230. [CrossRef] [PubMed]

5. Mok, C.C.; Lau, C.S. Pathogenesis of systemic lupus erythematosus. J. Clin. Pathol. 2003, 56, 481-490. [CrossRef] [PubMed]

6. Webber, D.; Cao, J.; Dominguez, D.; Gladman, D.D.; Levy, D.M.; Ng, L.; Paterson, A.D.; Touma, Z.; Urowitz, M.B.; Wither, J.E.; et al. Association of systemic lupus erythematosus (SLE) genetic susceptibility loci with lupus nephritis in childhood-onset and adult-onset SLE. Rheumatology 2020, 59, 90-98. [CrossRef] 
7. Munroe, M.E.; James, J.A. Genetics of lupus nephritis: Clinical implications. Semin. Nephrol. 2015, 35, 396-409. [CrossRef]

8. $\quad$ Bertsias, G.K.; Ioannidis, J.P.A.; Aringer, M.; Bollen, E.; Bombardieri, S.; Bruce, I.N.; Cervera, R.; Dalakas, M.; Doria, A.; Hanly, J.G.; et al. EULAR Recommendations for the Management of Systemic Lupus Erythematosus with Neuropsychiatric Manifestations: Report of a Task Force of the EULAR Standing Committee for Clinical Affairs. Ann. Rheum. Dis. 2010, 69, 2074-2082. [CrossRef]

9. Belot, A.; Rice, G.I.; Omarjee, S.O.; Rouchon, Q.; Smith, E.M.; Moreews, M.; Tusseau, M.; Frachette, C.; Bournhonesque, R.; Thielens, N.; et al. Contribution of rare and predicted pathogenic gene variants to childhood-onset lupus: A large, genetic panel analysis of British and French cohorts. Lancet Rheumatol. 2020, 2, e99-e109. [CrossRef]

10. Ballestar, E.; Esteller, M.; Richardson, B.C. The epigenetic face of Systemic Lupus Erythematosus. J. Immunol. 2006, 176, 7143-7147. [CrossRef]

11. Grimaldi, C.M. Sex and Systemic Lupus Erythematosus: The role of the sex hormones Estrogen and Prolactin on the regulation of autoreactive B cells. Curr. Opin. Rheumatol. 2006, 18, 456-461. [CrossRef] [PubMed]

12. Pan, L.; Lu, M.P.; Wang, J.H.; Xu, M.; Yang, S.R. Immunological pathogenesis and treatment of systemic lupus erythematosus. World. J. Pediatr. 2020, 16, 19-30. [CrossRef]

13. Sherer, Y.; Gorstein, A.; Fritzler, M.J.; Shoenfeld, Y. Autoantibody explosion in systemic lupus erythematosus: More than 100 different antibodies found in SLE patients. Semin. Arthritis Rheum. 2004, 34, 501-537. [CrossRef] [PubMed]

14. Lourenco, E.V.; Cava, A.L. Cytokines in systemic lupus erythematosus. Curr. Mol. Med. 2009, 9, $242-254$. [CrossRef] [PubMed]

15. Nam, S.; Xie, J.; Perkins, A.; Ma, Y.; Yang, F.; Wu, J.; Jove, R. Novel synthetic derivatives of the natural product berbamine inhibit Jak2/Stat3 signaling and induce apoptosis of human melanoma cells. Mol. Oncol. 2012, 6, 484-493. [CrossRef]

16. Crispín, J.C. Dysregulation of the serine/threonine phosphatase PP2A contributes to autoimmunity. Arthritis Res. Ther. 2012, 14, 1-28. [CrossRef]

17. Metry, A.M.; Al Salmi, I.; Al Balushi, F.; Yousef, M.A.; Al Ismaili, F.; Hola, A.; Hannawi, S. Systemic Lupus Erythematosus: Symptoms and Signs at Initial Presentations. Antiinflamm. Antiallergy Agents Med. Chem. 2019, 18, 142-150. [CrossRef]

18. Crispín, J.C.; Kyttaris, V.C.; Terhorst, C.; Tsokos, G.C. T Cells as Therapeutic Targets in SLE. Nat. Rev. Rheumatol. 2010, 6, 317-325. [CrossRef]

19. Shi, X.; Qian, T.; Li, M.; Chen, F.; Chen, Y.; Hao, F. Aberrant low expression of A20 in tumor necrosis factor- $\alpha$-stimulated SLE monocytes mediates sustained NF- $\mathrm{BB}$ inflammatory response. Immunol. Invest. 2015, 44, 497-508.

20. Xu, W.D.; Pan, H.F.; Ye, D.Q.; Xu, Y. Targeting IRF4 in autoimmune diseases. Autoimmun. Rev. 2012, 11, 918-924. [CrossRef]

21. Gorelik, G.; Richardson, B. Key role of ERK pathway signaling in lupus. Autoimmunity 2010, 43, 17-22. [CrossRef] [PubMed]

22. Patavino, T.; Brady, D.M. Natural medicine and nutritional therapy as an alternative treatment in systemic lupus erythematosus. Altern. Med. Rev. 2001, 6, 460-472. [PubMed]

23. Abrantes, V.E.F.; Rocha, B.A.M.D.; Nóbrega, R.B.D.; Silva-Filho, J.C.; Teixeira, C.S.; Cavada, B.S.; Gadelha, C.A.D.A.; Ferreira, S.H.; Figueiredo, J.G.; Santi-Gadelha, T.; et al. Molecular modeling of Lectin-like protein from Acacia farnesiana reveals a possible anti-inflammatory mechanism in carrageenan-induced inflammation. Biomed. Res. Int. 2013, 2013, 1-9. [CrossRef] [PubMed]

24. Bukoye, O.; Musbau, A. Immune modulation potentials of aqueous extract of Andrographis paniculata leaves in male rat. Researcher 2011, 3, 48-57.

25. Chung, J.W.; Choi, R.J.; Seo, E.K.; Nam, J.W.; Dong, M.S.; Shin, E.M.; Guo, L.Y.; Kim, Y.S. Anti-inflammatory effects of (Z)-Ligustilide through suppression of mitogen-activated protein kinases and Nuclear factor- $\mathrm{kB}$ activation pathways. Arch. Pharm. Res. 2012, 35, 723-732. [CrossRef]

26. Kaur, A.; Singh, J.; Kamboj, S.S.; Sexana, A.K.; Pandita, R.M.; Shamnugavel, M. Isolation of an $\mathrm{N}$-acetyl-D-glucosamine specific lectin from the rhizomes of Arundo donax with antiproliferative activity. Phytochemistry 2005, 66, 1933-1940. [CrossRef] 
27. Zesiorani, N.F.; Anwar, E. Transfersome gel formulation of an ethanol extract of apples (Malus domestica Mill) containing antioxidants and in vitro penetration testing using Franz diffusion cells. Int. J. App. Pharm. 2017, 9, 32-37. [CrossRef]

28. Mahapatra, S.K.; Chakraborty, S.P.; Roy, S. Immunomodulatory role of Ocimum gratissimum and ascorbic acid against nicotine-induced murine peritoneal macrophages in vitro. Oxid. Med. Cell Longev. 2011, 2011, 1-11. [CrossRef]

29. He, D.Y.; Dai, S.M. Anti-inflammatory and immunomodulatory effects of Paeonia lactiflora Pall, a traditional Chinese herbal medicine. Front. Pharmacol. 2011, 2, 1-5. [CrossRef]

30. Zeng, S.; Wang, D.; Cao, Y.; An, N.; Zeng, F.; Han, C.; Song, Y.; Deng, X. Immunopotentiation of Caffeoyl Glycoside from Picrorhiza scrophulariiflora on activation and cytokines secretion of immunocyte in vitro. Int. Immunopharmacol. 2008, 8, 1707-1712. [CrossRef]

31. Sun, X.G.; Fu, X.Q.; Cai, H.B.; Liu, Q.; Li, C.H.; Liu, Y.W.; Lv, Z.P. Proteomic analysis of protective effects of polysaccharides from Salvia miltiorrhiza against immunological liver injury in mice. Phytother. Res. 2011, 25, 1087-1094. [CrossRef] [PubMed]

32. Sheng, Y.; Li, L.; Holmgren, K.; Pero, R.W. DNA repair enhancement of aqueous extracts of Uncaria tomentosa in a human volunteer study. Phytomedicine 2001, 8, 275-282. [CrossRef] [PubMed]

33. Reis, S.R.I.; Valente, L.M.; Sampaio, A.L.; Siani, A.C.; Gandini, M.; Azeredo, E.L.; Kubelka, C.F. Immunomodulating and antiviral activities of Uncaria tomentosa on human monocytes infected with Dengue Virus-2. Int. Immunopharmacol. 2008, 8, 468-476. [CrossRef]

34. Chandrashekara, P.M.; Venkatesh, Y.P. Immunostimulatory properties of fructans derived from raw garlic (Allium Sativum, L.). Bioact. Carbohydr. Diet. Fibre 2016, 8, 65-70. [CrossRef]

35. Amirghofran, Z. Herbal medicines for immunosuppression. Iran. J. Allergy Asthma Immunol. 2012, 11, 111-119.

36. Ishida, M.; Nishi, K.; Kunihiro, N.; Onda, H.; Nishimoto, S.; Sugahara, T. Immunostimulatory effect of aqueous extract of Coriandrum sativum L. seed on macrophages. Sci. Food Agric. 2017, 97, 4727-4736. [CrossRef]

37. Chauhan, P.S.; Gupta, K.K.; Bani, S. The immunosuppressive effects of Agyrolobium roseum and Pinitol in experimental animals. Int. Immunopharmacol. 2011, 11, 286-291. [CrossRef]

38. Rahayu, R.P.; Prasetyo, R.A.; Purwanto, D.A.; Kresnoadi, U.; Iskandar, R.P.; Rubianto, M. The immunomodulatory effect of green tea (Camellia sinensis) leaves extract on immunocompromised Wistar rats infected by Candida albicans. Vet. World 2018, 11, 765-770.

39. Wan, Y.G.; Che, X.Y.; Sun, W.; Huang, Y.R.; Meng, X.J.; Chen, H.L.; Shi, X.M.; Tu, Y.; Wu, W.; Liu, Y.L. Low-dose of multi-glycoside of Tripterygium wilfordii Hook. f., a natural regulator of TGF- $\beta 1 / \mathrm{Smad}$ signaling activity improves adriamycin-induced glomerulosclerosis in vivo. J. Ethnopharmacol. 2014, 151, 1079-1089. [CrossRef]

40. Zhao, W.M.; Yang, Y.F.; Liu, Q.F.; Zhou, Y.; Tian, J.; Zhou, R. Periplocoside E, an effective compound from Periploca sepium Bge, inhibited $\mathrm{T}$ cell activation in vitro and in vivo. J. Pharmacol. Exp. Ther. 2006, 316, 662-669. [CrossRef]

41. Gandhi, M.; Shree, R. Immuno-modulatory effect of Turmeric (Curcuma longa) and Aloe vera on cultured Polymorphonuclear cells (PMN) and adherent mononuclear cells. Webmedcentral 2016, 7, 2-7.

42. Lim, S.L.; Goh, Y.M.; Noordin, M.M.; Rahman, H.S.; Othman, H.H.; Bakar, N.A.A.; Mohamed, S. Morinda citrifolia edible leaf extract enhanced immune response against lung cancer. Food Funct. 2016, 7, 741-751. [CrossRef] [PubMed]

43. Klippel, J.H. Systemic lupus erythematosus: Treatment-related complications superimposed on chronic disease. JAMA 1990, 263, 1812-1815. [CrossRef] [PubMed]

44. Wang, G.J.; Sweet, D.E.; Reger, S.I.; Thompson, R.C. Fat-cell changes as a mechanism of avascular necrosis of the femoral head in cortisone-treated rabbits. J. Bone Joint. Surg. Am. 1977, 59, 729-735. [CrossRef]

45. Richards, R.N. Side effects of short-term oral corticosteroids. J. Cutan. Med. Surg. 2008, 12, 77-81. [CrossRef]

46. Ficat, R.P. Idiopathic bone necrosis of the femoral head. Early diagnosis and treatment. J. Bone Joint. Surg. Am. 1985, 67, 3-9. [CrossRef]

47. Simkin, P.A.; Downey, D.J. Hypothesis: Retrograde embolization of marrow fat may cause osteonecrosis. J. Rheumatol. 1987, 14, 870-872. 
48. Cojocaru, M.; Cojocaru, I.M.; Silosi, I.; Vrabie, C.D. Manifestations of systemic lupus erythematosus. Maedica 2011, 6, 330-336.

49. Sostres, C.; Gargallo, C.J.; Arroyo, M.T.; Lanas, A. Adverse effects of non-steroidal anti-inflammatory drugs (NSAIDs, aspirin and coxibs) on upper gastrointestinal tract. Best Pract. Res. Clin. Gastroenterol. 2010, 24, 121-132. [CrossRef]

50. Crofford, L.J.; Lipsky, P.E.; Brooks, P.; Abramson, S.B.; Simon, L.S.; Leo, B.A. Van De Putte. Basic Biology and Clinical Application of Specific Cyclooxygenase-2 Inhibitors. Arthritis Rheum. 2000, 43, 4-13. [CrossRef]

51. Østensen, M.; Villiger, P.M. Nonsteroidal anti-inflammatory drugs in systemic lupus erythematosus. Lupus 2001, 10, 135-139. [CrossRef] [PubMed]

52. Ruiz-Irastorza, G.; Khamashta, M.A. Hydroxychloroquine: The cornerstone of lupus therapy. Lupus 2008, 17, 271-273. [CrossRef] [PubMed]

53. Lafyatis, R.; York, M.; Marshak-Rothstein, A. Antimalarial agents: Closing the gate on toll-like receptors? Arthr. Rheum. 2006, 54, 3068-3070. [CrossRef] [PubMed]

54. Kuhn, A.; Bonsmann, G.; Anders, H.J.; Herzer, P.; Tenbrock, K.; Schneider, M. The diagnosis and treatment of systemic lupus erythematosus. Dtsch. Arztebl. Int. 2015, 112, 423-432.

55. Vallerskog, T.; Gunnarsson, I.; Widhe, M.; Risselada, A.; Klareskog, L.; van Vollenhoven, R.; Trollmo, C. Treatment with rituximab affects both the cellular and the humoral arm of the immune system in patients with SLE. Clin. Immunol. 2007, 122, 62-74. [CrossRef] [PubMed]

56. Pers, J.O.; Daridon, C.; Devauchelle, V.; Jousse, S.; Saraux, A.; Jamin, C.; Youinou, P. BAFF overexpression is associated with autoantibody production in autoimmune diseases. Ann. N. Y. Acad. Sci. 2005, 1050, 34-39. [CrossRef] [PubMed]

57. Dasgupta, A.; Hammett-Stabler, C.A. Herbal Supplements: Efficacy, Toxicity, Interactions with Western Drugs and Effects on Clinical Laboratory Tests, 1st ed.; John Wiley \& Son: Hoboken, NJ, USA, 2011; pp. 135-154.

58. Ziaei, A.; Hoppstädter, J.; Kiemer, A.K.; Ramezani, M.; Amirghofran, Z.; Diesel, B. Inhibitory effects of teuclatriol, a sesquiterpene from salvia mirzayanii, on nuclear factor- $\kappa \mathrm{B}$ activation and expression of inflammatory mediators. J. Ethnopharmacol. 2015, 160, 94-100. [CrossRef]

59. Upadhyay, R.K. Nutraceutical, pharmaceutical and therapeutic uses of Allium cepa: A review. Int. J. Green Pharm. 2016, 10, S46-S64.

60. Kala, C.; Ali, S.S.; Khan, N.A. Immunostimulatory potential of n-butanolic fraction of hydroalcoholic extract of Costus speciosus koen. Rhizome. Int. J. Pharm. Sci. Res. 2015, 6, 2886-2892.

61. Thangam, R.; Sathuvan, M.; Poongodi, A.; Suresh, V.; Pazhanichamy, K.; Sivasubramanian, S.; Kannan, S. Activation of intrinsic apoptotic signaling pathway in cancer cells by Cymbopogon citratus polysaccharide fractions. Carbohydr. Polym. 2014, 107, 138-150. [CrossRef]

62. Yin, Y.; Gong, F.Y.; Wu, X.X.; Sun, Y.; Li, Y.H.; Chen, T.; Xu, Q. Anti-inflammatory and immunosuppressive effect of flavones isolated from Artemisia vestita. J. Ethnopharmacol. 2008, 120, 1-6. [CrossRef] [PubMed]

63. Sani, T.A.; Mohammadpour, E.; Mohammadi, A.; Memariani, T.; Yazdi, M.V.; Rezaee, R.; Shahsavand, S. Cytotoxic and apoptogenic properties of Dracocephalum kotschyi aerial part different fractions on calu- 6 and mehr-80 lung cancer cell lines. Farmacia 2017, 65, 189-199.

64. Faham, N.; Javidnia, K.; Bahmani, M.; Amirghofran, Z. Calycopterin, an immunoinhibitory compound from the extract of Dracocephalum kotschyi. Phytother. Res. 2008, 22, 1154-1158. [CrossRef] [PubMed]

65. Haija, A.J.; Schulz, S.W. The role and effect of complementary and alternative medicine in Systemic Lupus Erythematosus. Rheum. Dis. Clin. North. Am. 2011, 37, 47-62. [CrossRef]

66. Jiao, B.; Gao, J. Intensive research on the prospective use of complementary and alternative medicine to treat systemic lupus erythematosus. Drug Discov. Ther. 2013, 7, 167-171. [CrossRef]

67. Moore, A.D.; Petri, M.A.; Manzi, S.; Isenberg, D.A.; Gordon, C.; Senécal, J.L.; Sutcliffe, N. The use of alternative medical therapies in patients with systemic lupus erythematosus. Arthr. Rheum. 2000, 43, 1410-1418. [CrossRef]

68. Yarnell, E.; Abascal, K. Lupus Erythematosus and Herbal Medicine. Altern. Complement. Ther. 2008, 14, 1-10. [CrossRef]

69. Alvarez-Nemegyei, J.; Bautista-Botello, A. Complementary or Alternative therapy use and health status in Systemic Lupus Erythematosus. Lupus 2009, 18, 159-163. [CrossRef] 
70. Greco, C.M.; Nakajima, C.; Manzi, S. Updated Review of Complementary and Alternative Medicine Treatments for Systemic Lupus Erythematosus. Curr. Rheumatol. Rep. 2013, 15, 1-9. [CrossRef]

71. Prasanna, V.K.; Venkatesh, Y.P. Characterization of onion lectin (Allium cepa agglutinin) as an immunomodulatory protein inducing Th1-type immune response in vitro. Int. Immunopharmacol. 2015, 26, 304-313. [CrossRef] 